\title{
Satavaptan for the management of ascites in cirrhosis: efficacy and safety across the spectrum of ascites severity
}

\author{
Florence Wong, ${ }^{1}$ Hugh Watson, ${ }^{2}$ Alexander Gerbes, ${ }^{3}$ Hendrik Vilstrup, ${ }^{4}$ \\ Salvatore Badalamenti, ${ }^{5}$ Mauro Bernardi, ${ }^{6}$ Pere Ginès, ${ }^{7}$ for the Satavaptan \\ Investigators Group
}

\begin{abstract}
- Additional tables and figures are published online only. To view these files please visit the journal online (http://gut.bmj. com)

'Department of Medicine, Toronto General Hospital, University of Toronto, Toronto, Ontario, Canada

${ }^{2}$ Sanofi Aventis R\&D, Paris, France

${ }^{3}$ Liver Center Munich, Department of Medicine 2, Klinikum of the

LMU-Grosshadern, University of Munich, Munich, Germany

${ }^{4}$ Department of Medicine V (Hepatology and

Gastroenterology), Aarhus University Hospital, Aarhus, Denmark

${ }^{5}$ Sanofi Aventis R\&D, Bridgewater, New Jersey, USA ${ }^{6}$ Dipartimento di Medicina Clinica, Alma Mater Studiorum, Semeiotica Medica, Policlinico S. Orsola-Malpighi, University of Bologna, Bologna, Italy ${ }^{7}$ Liver Unit, Hospital Clinic, University of Barcelona, IDIBAPS (Institut d'Investigacions Biomèdiques August Pi-Sunyer), CIBEReHD (Centro de Investigación Biomédica en Red Enfermedades Hepáticas y Digestivas), Barcelona, Catalunya, Spain
\end{abstract}

Correspondence to Dr Pere Ginès, Liver Unit, Hospital Clinic, University of Barcelona, Barcelona, Spain; pgines@clinic.ub.es

Revised 28 June 2011 Accepted 12 July 2011 Published Online First 11 August 2011

\section{ABSTRACT}

Objective Satavaptan, a vasopressin V2 receptor antagonist, has been shown to improve the control of ascites in cirrhosis in short-term phase II studies. The aim of this study was to evaluate the efficacy and safety of satavaptan in three different populations of patients with cirrhosis and ascites.

Methods 1200 patients were included in three randomised double-blind studies comparing satavaptan with placebo in uncomplicated ascites (study 1: $n=463$ patients) and difficult-to-treat ascites, with and without concomitant diuretic treatment (studies 2 and $3: n=497$ and $n=240$ patients, respectively).

Results Satavaptan was not more effective than placebo in the control of ascites in any of the populations studied as estimated by the primary efficacy endpoints: worsening of ascites (study 1) and the cumulative number of largevolume paracenteses during 12 weeks (studies 2 and 3). Nevertheless, some of the secondary efficacy endpoints related to the treatment of ascites were met in the three studies, suggesting a slight advantage of satavaptan over placebo in delaying ascites formation. Moreover, satavaptan was more effective than placebo in improving the serum sodium concentration in patients with hyponatraemia. The incidence of major complications of cirrhosis during follow-up did not differ significantly between the satavaptan and placebo groups in the three studies. Overall, the rate of any treatment-related adverse events, serious treatment-related events and treatmentrelated events leading to permanent discontinuation of treatment did not differ significantly between the treatment groups. However, in study 2 mortality was higher in patients treated with satavaptan compared with placebo (HR 1.47; 95\% Cl 1.01 to 2.15); no significant differences in mortality between the two groups were observed in the other two studies. No specific cause for the increased mortality was identified. Most deaths were associated with known complications of liver cirrhosis. Conclusion Satavaptan, alone or in combination with diuretics, is not clinically beneficial in the long-term management of ascites in cirrhosis.

The management of ascites in patients with cirrhosis can be difficult because patients either do not respond to diuretics or they develop complications during treatment. ${ }^{1-4}$ In the last 40 years no significant advances have been made in the pharmacological therapy of ascites in cirrhosis. Recently,

\section{Significance of this study}

What is already known about this subject?

- The pharmacological management of ascites in cirrhosis is unsatisfactory in some patients because of a lack of response to treatment with standard diuretics.

- Patients with cirrhosis and ascites generally have increased secretion of vasopressin from the neurohypophysis which participates in the pathogenesis of fluid retention.

- Vaptans are a new family of orally active drugs that increase urine volume by antagonising specifically the vasopressin V2 receptors in the principal cells of the collecting ducts that have been shown to reduce ascites in phase II studies.

\section{What are the new findings?}

- The V2 vasopressin antagonist satavaptan is more effective than placebo on a long-term basis in increasing the serum sodium concentration in patients with cirrhosis, ascites and hyponatraemia.

- The V2 vasopressin antagonist satavaptan only offers a marginal beneficial effect compared with conventional treatment in the management of ascites in cirrhosis.

How might it impact on clinical practice in the foreseeable future?

- The combination of diuretics and vasopressin V2 antagonists does not seem to be an effective approach for the long-term management of ascites and oedema in cirrhosis.

- The use of vaptans in cirrhosis should be restricted to the management of hypervolaemic hyponatraemia. Appropriately designed longterm studies assessing the efficacy and safety of vaptans for this indication are needed.

a new family of drugs that increase urine volume has been developed. ${ }^{5}$ These drugs, known as vaptans, act by antagonising selectively the renal vasopressin V2 receptors causing an increase in solute-free water excretion and serum sodium concentration. ${ }^{5}$ Some of these drugs have been approved in several countries for the management 
of hypervolaemic hyponatraemia in association with cirrhosis and ascites, heart failure and syndrome of inappropriate antidiuretic hormone secretion. ${ }^{6}$ Short-term phase II studies with the $\mathrm{V} 2$ receptor antagonist satavaptan in patients with cirrhosis and ascites have shown that it decreases ascites volume and the need for large-volume paracentesis (LVP).$^{8-10}$ The current studies were therefore designed to test whether long-term satavaptan administration may improve ascites in cirrhosis. The current report describes the results of three large randomised double-blind comparative studies of satavaptan versus placebo in three different populations of patients with cirrhosis and ascites.

\section{METHODS}

\section{Patient population and design of studies}

One thousand and two hundred patients with cirrhosis and ascites were included in three multicentre randomised doubleblind studies comparing satavaptan with placebo. The studies were performed between July 2006 and December 2008. They were approved by the appropriate regulatory agencies and ethics committees for each participating institution and registered on a public website (http://www.ClinicalTrials.gov registration numbers NCT00358878, NCT00359437 and NCT00366795). All patients gave written informed consent to participation.

The target populations were different in the three studies (see later) but the exclusion criteria were identical. Patients with a history of variceal bleeding or bacterial peritonitis in the previous 10 days or hepatic encephalopathy grade $>1$ at the time of randomisation were excluded; however, these patients could be included at a later date. Other main reasons for exclusion of patients were serum creatinine $>151 \mu \mathrm{mol} / 1(1.7 \mathrm{mg} / \mathrm{dl})$, serum potassium $>5.5 \mathrm{mmol} / \mathrm{l}$, serum sodium $>143 \mathrm{mmol} / \mathrm{l}$, serum bilirubin $>150 \mu \mathrm{mol} / 1$, INR $>3.0$, platelets $<30000 / \mathrm{mm}^{3}$, neutrophils $<1000 / \mathrm{mm}^{3}$, shock or hepatocellular carcinoma exceeding the Milan criteria. Concomitant administration of potent or moderate inhibitors of the cytochrome P450 3A pathway or drugs known to increase the risk of OT interval prolongation was not permitted during the studies.

The dose regimen of satavaptan was based on previous phase II studies ${ }^{8-10}$ and was the same for each study, commencing with a dose of $5 \mathrm{mg}$ /day on the day of randomisation and maintaining this daily dose for the first 7 days, following which the dose could be increased to $10 \mathrm{mg}$ /day according to the investigator's judgement based on efficacy and tolerability. Subsequent adjustments of the dose to $5 \mathrm{mg}$ /day or $10 \mathrm{mg}$ /day could be made at any time as considered necessary. Duration of treatment was 52 weeks in all three studies. The exposure to the study drug and the average dose of satavaptan given in each of the three studies are shown in table 1 in the online supplement.

Patients were followed up at intervals of no more than 4 weeks. Assessments of clinical status including ascites and adverse events were recorded at each visit. Blood samples were taken for serum chemistry and haematology at each visit and analysed at a central laboratory. ECGs were also performed at each visit and analysed by a central reader. Patients in all studies were followed up for safety for 52 weeks after randomisation, even in the case of early treatment discontinuation, in order to obtain accurate estimates of mortality.

Study 1: Satavaptan versus placebo in combination with diuretics in the management of ascites not requiring LVP

The objective of this study was to evaluate the efficacy and safety of satavaptan in addition to conventional treatment in the management of ascites. Patients studied were those with clinically evident ascites being treated with a sodium-restricted diet with or without diuretics and no history of repeated LVP in the previous 6 months.

The planned sample size was a minimum of 440 patients. Patients were randomised in a 1:1 ratio to receive satavaptan or placebo with stratification for serum sodium ( $<$ or $\geq 135 \mathrm{mmol} /$ l) and current diuretic regimen (none, potassium-sparing diuretic alone or any other diuretic alone or combination). Patients continued on their sodium-restricted diet ( $<88 \mathrm{mmol} /$ day) and current regimen of diuretic agents. The primary efficacy endpoint was the worsening of ascites during the first 12 weeks of the study, defined as LVP and/or weight increase of $\geq 2 \mathrm{~kg}$ since the baseline measurement (including the weight of any ascitic fluid removed by LVP) and/or premature study discontinuation.

Other ascites endpoints evaluated were: (1) time to reduction of ascites, defined as a decrease in body weight of $\geq 2 \mathrm{~kg}$ compared with baseline without any LVP or increase in diuretic regimen; (2) worsening of ascites during the first 24 weeks using a threshold of $4 \mathrm{~kg}$ body weight increase from baseline; (3) time to first LVP; (4) cumulative number of LVPs; and (5) cumulative increase in ascites estimated by the addition of weight change since randomisation and the weight of any ascitic fluid drained by LVP.

Non-ascites endpoints evaluated included the risk of other major complications of cirrhosis such as hepatic encephalopathy, spontaneous bacterial peritonitis, variceal bleeding and renal impairment (defined as serum creatinine increase over baseline $>50 \%$ to a level $>133 \mu \mathrm{mol} / \mathrm{l}$ or $1.5 \mathrm{mg} / \mathrm{dl}$ ). Time to correction of hyponatraemia ( $>135 \mathrm{mmol} / \mathrm{l}$ ) was also evaluated in patients with a starting serum sodium level $\leq 130 \mathrm{mmol} / \mathrm{l}$.

Study 2: Satavaptan versus placebo in combination with diuretics in the prevention of recurrent ascites after LVP

The objective of this study was to evaluate the efficacy and safety of satavaptan in addition to diuretics in the prevention of recurrence of ascites in patients with a history of frequent LVP. Patients studied were those with recurrent ascites having a LVP of at least 4 litres less than $24 \mathrm{~h}$ before randomisation and with a history of at least one other LVP in the previous 3 months. All patients had to be receiving a sodium-restricted diet and one or more diuretic agents.

The planned sample size was a minimum of 450 patients. Patients were randomised in a 2:1 ratio to receive satavaptan or placebo with stratification for diuretic regimen (as for study 1) and for the interval between the two previous paracenteses ( $\leq$ or $>28$ days). Patients continued on their sodium-restricted diet and current regimen of diuretic agents.

The primary efficacy endpoint was the cumulative number of LVPs (defined as the removal of at least 1 litre of ascites) during the first 12 weeks of the study. Other ascites endpoints evaluated were: (1) time to first LVP; (2) time to recurrence of ascites, defined as LVP and/or weight increase of $\geq 4 \mathrm{~kg}$ since the baseline measurement; and (3) cumulative increase in ascites estimated by the addition of weight change since randomisation and the weight of any ascitic fluid drained by LVP.

Non-ascites endpoints evaluated included the risk of other major complications of cirrhosis (see study 1) and time to correction of hyponatraemia.

\section{Study 3: Satavaptan versus placebo as single therapy in the prevention of recurrent ascites after LVP}

The objective of this study was to evaluate the efficacy and safety of satavaptan in the prevention of recurrence of ascites in 
patients with a history of frequent LVP not being treated with diuretics because of refractory ascites.

Patients studied were those with recurrent ascites having a LVP of at least 4 litres less than $24 \mathrm{~h}$ before randomisation and a history of at least one other LVP in the previous 3 months. Patients had to be receiving a sodium-restricted diet but were unsuitable for treatment with diuretic agents and such drugs were not to be administered during the first 12 weeks of the study.

The planned sample size was a minimum of 225 patients. Patients were randomised in a 2:1 ratio to receive satavaptan or placebo with stratification for baseline serum sodium (as for study 1) and the interval between the two previous LVPs (as for study 2). Patients continued on their sodium-restricted diet. The primary efficacy endpoint was the cumulative number of LVPs (of at least 1 litre of ascites) during the first 12 weeks of the study.

Other ascites endpoints evaluated were: (1) time to first LVP; (2) time to recurrence of ascites, defined as LVP and/or weight increase of $\geq 4 \mathrm{~kg}$ since the baseline measurement; and (3) cumulative increase in ascites estimated by the addition of weight change since randomisation and the weight of any ascitic fluid drained by LVP.

Non-ascites endpoints evaluated included the risk of other major complications of cirrhosis (see study 1) and time to correction of hyponatraemia.

\section{Statistical methods}

The planned sample sizes were calculated based on data from completed phase II studies $^{8-10}$ to give studies sufficient power to detect HRs of satavaptan versus placebo of 0.6 (study 1), 0.7 (study 2) and 0.7 (study 3) in the primary efficacy endpoint, with a power of at least $90 \%$ at the $5 \%$ significance level.

Analysis methods were designed to take into account variations in duration of exposure and observation, as a high rate of discontinuation could be expected in studies of patients with end-stage liver disease. The intent-to-treat population (all patients randomised and exposed to treatment) was used for analysis. Cumulative numbers of events over time were analysed using Nelson-Aalen estimates and a Cox model for recurrent events. Time to first event was analysed using Kaplan-Meier estimates and a Cox model. The rate of ascites accumulation was estimated by comparing the slopes in a regression analysis of the volume over time, taking into account the individual weight change, total volume of ascites removed by LVP and duration of observation. p Values $<0.05$ were considered statistically significant. Primary efficacy analyses were adjusted for the following baseline covariates: serum sodium, concomitant diuretic regimen (studies 1 and 2), interval between the two previous LVPs (studies 2 and 3 ) and geographical region.

\section{RESULTS \\ Study 1: Satavaptan versus placebo in combination with diuretics in the management of ascites in patients not requiring LVP}

The disposition of all the patients is shown in figure 1 in the online supplement. The two treatment arms were well-matched at baseline for demographic and disease characteristics (table 1). The duration of exposure to study drug and the use of concomitant diuretics was similar in the two treatment arms (see tables 1 and 2 in online supplement).

There was no statistically significant effect in the first 12 weeks in the incidence of worsening ascites in the satavaptan
Table 1 Baseline characteristics of patients in study 1: satavaptan versus placebo in combination with diuretics in the management of ascites not requiring large-volume paracentesis

\begin{tabular}{lccc}
\hline & $\begin{array}{l}\text { Placebo } \\
\text { (N=230) }\end{array}$ & $\begin{array}{l}\text { Satavaptan } \\
\text { (N=232) }\end{array}$ & $\begin{array}{l}\text { All } \\
\text { (N=462) }\end{array}$ \\
\hline Age, years & $56.4(9.2)$ & $56.6(10.2)$ & $56.5(9.7)$ \\
Sex & & & \\
$\quad$ Men & $168(73.0 \%)$ & $158(68.1 \%)$ & $326(70.6 \%)$ \\
$\quad$ Women & $62(27.0 \%)$ & $74(31.9 \%)$ & $136(29.4 \%)$ \\
Aetiology of cirrhosis, $\mathrm{n}^{*}$ & & & \\
$\quad$ Alcoholism & $151(65.7 \%)$ & $148(63.8 \%)$ & $299(64.7 \%)$ \\
$\quad$ Hepatitis C & $49(21.3 \%)$ & $61(26.3 \%)$ & $110(23.8 \%)$ \\
$\quad$ Hepatitis B & $20(8.7 \%)$ & $18(7.8 \%)$ & $38(8.2 \%)$ \\
$\quad$ Others & $39(17.0 \%)$ & $38(16.4 \%)$ & $77(16.7 \%)$ \\
Child-Pugh score & $8.0(1.6)$ & $7.9(1.5)$ & $7.9(1.5)$ \\
Child-Pugh class C, $\mathrm{n}$ & $45(19.6 \%)$ & $33(14.2 \%)$ & $78(16.9 \%)$ \\
MELD score & $13.1(3.8)$ & $12.8(4.4)$ & $13.0(4.1)$ \\
MELD-Na score & $14.6(5.7)$ & $14.2(5.9)$ & $14.4(5.8)$ \\
Serum bilirubin, $\mu$ mol/l & $36(29)$ & $33(26)$ & $35(27)$ \\
Serum creatinine, $\mu$ mol/l & $80(22)$ & $79(23)$ & $79(22)$ \\
Serum sodium, mmol/l & $137(4.5)$ & $137(4.2)$ & $137(4.3)$ \\
Ascites grade, $\mathrm{n}$ & & & \\
$\quad$ Mild & $91(39.6 \%)$ & $85(36.6 \%)$ & $176(38.1 \%)$ \\
$\quad$ Moderate & $126(54.8 \%)$ & $127(54.7 \%)$ & $253(54.8 \%)$ \\
$\quad$ Marked & $13(5.7 \%)$ & $20(8.6 \%)$ & $33(7.1 \%)$ \\
History of any paracentesis, $\mathrm{n}$ & $96(41.7 \%)$ & $105(45.3 \%)$ & $201(43.5 \%)$ \\
Time since last paracentesis, days & $427(912)$ & $318(494)$ & $370(725)$ \\
History of hepatic encephalopathy, $\mathrm{n}$ & $55(23.9 \%)$ & $44(19.0 \%)$ & $99(21.4 \%)$ \\
\hline
\end{tabular}

Values are mean (SD) or $n(\%)$.

*Some patients may have more than one aetiology of cirrhosis.

MELD, model for end-stage liver disease.

group compared with the placebo group, although there was a tendency for a better control of ascites in the satavaptan group (RR 0.85, 95\% CI 0.67 to $1.09, p=0.2034$; figure 1). There was also no statistically significant difference between the two groups over 52 weeks of treatment. Similar results were observed whether using the threshold of $2 \mathrm{~kg}$ or $4 \mathrm{~kg}$ to define worsening of ascites.

The time to reduction of ascites was shorter in those receiving satavaptan than in the placebo group (RR 1.48, 95\% CI 1.12 to 1.94, $\mathrm{p}=0.005$ ), a difference which emerged during the first 2 weeks of treatment (see figure 2 in online supplement). Time to first LVP (RR $0.75,95 \%$ CI 0.49 to 1.46 ) and the cumulative number of LVPs over 52 weeks (RR $0.79,95 \%$ CI 0.52 to 1.20 ) were not significantly improved by satavaptan. The mean cumulative increase in estimated ascites was lower in the satavaptan group but the difference was not statistically significant $(0.12 \mathrm{l} /$ week for satavaptan vs $0.21 \mathrm{l}$ /week for placebo, a ratio of $0.58,95 \%$ CI 0.07 to 1.09 ).

In patients with significant hyponatraemia at study entry, the median time to correction of hyponatraemia was 8 days on satavaptan compared with 43 days for placebo (RR 2.91, 95\% CI 1.47 to 5.75). The percentage of patients in the study with a serum sodium level $>145 \mathrm{mmol} / \mathrm{l}$ on at least one occasion was $15.2 \%$ in the satavaptan group and $9.6 \%$ in the placebo group. Two patients on satavaptan and one patient on placebo had an initial increase in serum sodium of $\geq 8 \mathrm{mmol} / 1$ in the $24 \mathrm{~h}$ following the first dose of the study treatment. The maximum increase in 1 day was $10 \mathrm{mmol} / \mathrm{l}$. These changes were not associated with any adverse clinical events.

The incidence of major complications of cirrhosis did not differ significantly between the two treatment arms (see table 3 in online supplement). Tests for renal function (including serum creatinine and estimated glomerular filtration rate using the 
Figure 1 Kaplan-Meier analysis of time to worsening ascites in study 1 : satavaptan versus placebo in combination with diuretics in the management of ascites not requiring large-volume paracentesis. Median time to event: satavaptan 9.2 weeks, placebo 7.4 weeks (RR $0.85,95 \% \mathrm{Cl}$ 0.67 to 1.09 ).

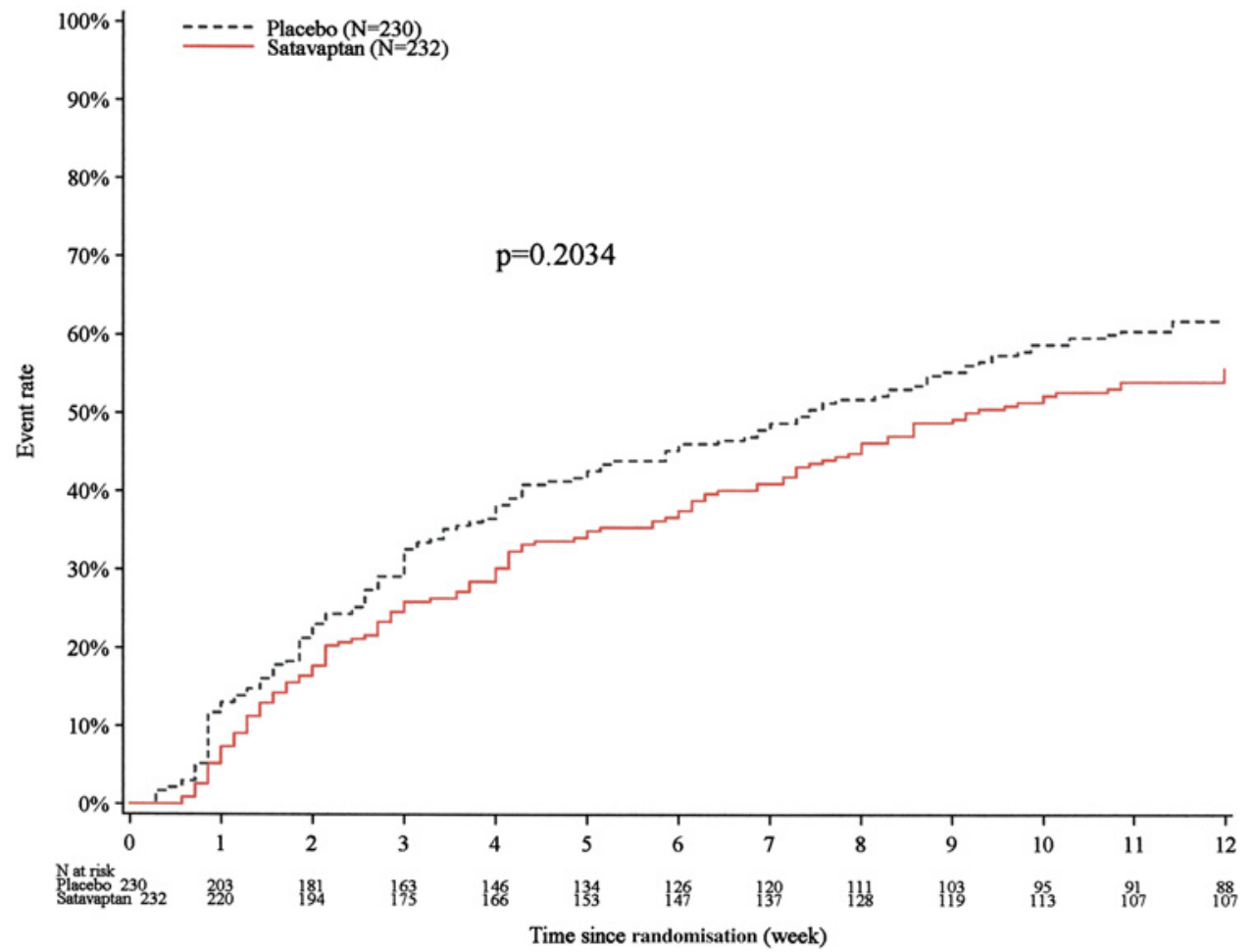

modified diet in renal disease (MDRD) formula), ${ }^{11}$ liver function, other serum chemistry and haematological parameters and ECGs did not show any differences between the treatment groups. No significant differences in the effects on blood pressure and heart rate were observed between the two groups (see table 4 in online supplement).

Overall, the percentage of treatment-related adverse events (84.9\% for satavaptan vs $86.1 \%$ for placebo), serious treatmentrelated events $(47.4 \%$ vs $49.6 \%$ ) and treatment-related events leading to permanent discontinuation of treatment $(24.1 \%$ vs $22.2 \%$ ) were similar for the two treatment groups.

During the 52 weeks of follow-up, $20.3 \%$ of patients in the satavaptan group and $17.4 \%$ of those in the placebo group died (RR for all-cause mortality during or after treatment $1.18,95 \%$ CI 0.78 to 1.81; see figure 3 in online (supplement). The incidence of treatment-related events with a fatal outcome was higher in the satavaptan group than in the placebo group $(12.5 \%$ vs $6.1 \%$ ) but did not reach statistical significance (RR 2.01, 95\% CI 1.06 to 3.80 ). Most deaths were associated with known complications of cirrhosis (table 2).

\section{Study 2: Satavaptan versus placebo in combination with diuretics in the prevention of recurrent ascites after LVP}

The disposition of all the patients is shown in figure 4 in the online supplement. After completion of enrollment but before the treatment of all patients had been completed, the Drug Safety Monitoring Board recommended the early termination of this study due to an increased mortality in the satavaptan group. At that time, 64 patients $(19.3 \%)$ in the satavaptan group and 33 patients $(19.5 \%)$ in the placebo group were still receiving treatment.

The two treatment arms were well-matched at baseline for demographic and disease characteristics (table 3). The mean duration of exposure to study treatment and concomitant diuretic use were similar in the two groups (see tables 1 and 2 in online supplement).
There was no statistically significant effect of satavaptan in the first 12 weeks on the cumulative number of LVPs compared with the placebo group (RR $0.89,95 \%$ CI 0.76 to $1.05, p=0.17$; figure 2). The mean volume of ascites removed per LVP was 6.6 litres in the satavaptan group and 6.9 litres in the placebo group. There was also no statistical difference in the number of LVPs over 52 weeks of treatment.

The time to first LVP (RR $0.79,95 \%$ CI 0.63 to $0.98, p=0.03$ ) and time to first recurrence of ascites (RR $0.74,95 \%$ CI 0.60 to $0.90, p=0.0032$; figure 5 in online supplement) were both increased by satavaptan compared with placebo ( 25 days vs 22 days and 14 days vs 11 days, respectively). The mean estimated increase in ascites volume was lower in the satavaptan group than in the placebo group (2.0 l/week vs $2.4 \mathrm{l} /$ week, respectively, a ratio of $0.83,95 \%$ CI 0.69 to $0.96, p=0.02$ ).

In patients with significant hyponatraemia at study entry, the median time to correction of hyponatraemia was 8 days for the satavaptan group and 43 days for the placebo group (RR 1.97, 95\% CI 1.97 to 3.34). The percentage of patients in the study with a serum sodium level $>145 \mathrm{mmol} / \mathrm{l}$ was higher in the satavaptan group than in the placebo group (9.5\% vs $3.6 \%)$. Six patients on satavaptan compared with no patient on placebo had an initial increase in serum sodium of $\geq 8 \mathrm{mmol} / 1$ in the $24 \mathrm{~h}$ following the first dose of the study treatment. The maximum increase was $10 \mathrm{mmol} / \mathrm{l}$ and these changes were not associated with any adverse clinical events.

The incidence of other major complications of cirrhosis did not differ significantly between the two treatment arms (see table 5 in online supplement).

During follow-up, significant increases in transaminases and serum bilirubin (threefold) were more frequent in the satavaptan group than in the placebo group (alanine aminotransferase $11.6 \%$ vs $6.0 \%$, aspartate transaminase $9.5 \%$ vs $3.0 \%$, bilirubin $8.8 \%$ vs $4.8 \%$ ). In contrast, comparison of renal function tests (serum creatinine and MDRD), other serum chemistries and haematological parameters, arterial pressure, heart rate 
Table 2 Causes of death in the three studies

\begin{tabular}{lcc}
\hline Study 1 & Placebo (n= 230) & Satavaptan (n= 232) \\
\hline Hepatic encephalopathy & $5(2.2 \%)$ & $4(1.7 \%)$ \\
Variceal bleeding & $5(2.2 \%)$ & $3(1.3 \%)$ \\
Bacterial infections & $6(2.6 \%)$ & $12(5.2 \%)$ \\
Renal impairment & $2(0.9 \%)$ & $6(2.6 \%)$ \\
Liver failure & $10(4.3 \%)$ & $7(3.0 \%)$ \\
Non-hepatic causes & $12(5.2 \%)$ & $15(6.5 \%)$ \\
Total deaths (all causes) & $40(17.4 \%)$ & $47(20.3 \%)$ \\
\hline Study 2 & Placebo (n=168) & Satavaptan (n=328) \\
\hline Hepatic encephalopathy & $5(3.0 \%)$ & $8(2.4 \%)$ \\
Variceal bleeding & $1(0.6 \%)$ & $11(3.3 \%)$ \\
Bacterial infections & $11(6.5 \%)$ & $20(6.1 \%)$ \\
Renal impairment & $6(3.6 \%)$ & $15(4.6 \%)$ \\
Liver failure & $9(5.4 \%)$ & $16(4.9 \%)$ \\
Non-hepatic causes & $5(3.0 \%)$ & $31(9.5 \%)^{*}$ \\
Total deaths (all causes) & $37(22.3 \%)$ & $101(30.6 \%)$ \\
\hline Study 3 & Placebo (n= 80) & Satavaptan (n= 160) \\
\hline Hepatic encephalopathy & $0(0 \%)$ & $8(5.0 \%)$ \\
Variceal bleeding & $2(2.6 \%)$ & $8(5.0 \%)$ \\
Bacterial infections & $7(8.8 \%)$ & $16(10.0 \%)$ \\
Renal impairment & $1(1.3 \%)$ & $8(5.0 \%)$ \\
Liver failure & $13(16.3 \%)$ & $11(6.9 \%)$ \\
Non-hepatic causes & $4(5.0 \%)$ & $4(2.5 \%)$ \\
Total deaths (all causes) & $27(34.2 \%)$ & $55(34.2 \%)$ \\
\hline
\end{tabular}

*Non-hepatic causes of death in study 2 included hypovolaemia, thromboembolic disorders, cardiac events, respiratory disorders, cancers and accidents (falls).

(see table 4 in online supplement) and ECGs did not show any consistent differences between the treatment groups.

Overall, the percentage of patients with any treatment-related adverse events $(87.9 \%$ for satavaptan vs $86.7 \%$ for placebo), serious treatment-related events $(60.0 \%$ vs $54.8 \%)$ and treat-

Table 3 Baseline characteristics of patients included in study 2: satavaptan versus placebo in combination with diuretics in the prevention of recurrent ascites after large-volume paracentesis

\begin{tabular}{|c|c|c|c|}
\hline & $\begin{array}{l}\text { Placebo } \\
(N=168)\end{array}$ & $\begin{array}{l}\text { Satavaptan } \\
(\mathrm{N}=328)\end{array}$ & $\begin{array}{l}\text { All } \\
(\mathrm{N}=496)\end{array}$ \\
\hline Age, years & $57.0(9.8)$ & $58.9(10.0)$ & $58.3(10.0)$ \\
\hline \multicolumn{4}{|l|}{ Sex } \\
\hline Men & $113(67.3 \%)$ & $237(72.3 \%)$ & $350(70.6 \%)$ \\
\hline Women & $55(32.7 \%)$ & $91(27.7 \%)$ & $146(29.4 \%)$ \\
\hline \multicolumn{4}{|l|}{ Aetiology of cirrhosis, $\mathrm{n}^{*}$} \\
\hline Alcoholism & $122(72.6 \%)$ & $251(76.5 \%)$ & $373(75.2 \%)$ \\
\hline Hepatitis B & $17(10.1 \%)$ & $27(8.2 \%)$ & $44(8.9 \%)$ \\
\hline Hepatitis C & $34(20.2 \%)$ & $53(16.2 \%)$ & $87(17.5 \%)$ \\
\hline Others & $23(13.7 \%)$ & $38(11.6 \%)$ & $61(12.3 \%)$ \\
\hline Child-Pugh score & $8.8(1.4)$ & $8.8(1.5)$ & $8.8(1.5)$ \\
\hline Child-Pugh class $\mathrm{C}, \mathrm{n}$ & $48(28.6 \%)$ & $100(30.6 \%)$ & $148(29.9 \%)$ \\
\hline MELD score & $13.3(3.9)$ & $13.3(3.8)$ & $13.3(3.8)$ \\
\hline MELD-Na score & $15.4(6.2)$ & $15.5(6.3)$ & $15.5(6.2)$ \\
\hline Serum bilirubin, $\mu \mathrm{mol} / \mathrm{l}$ & $35(26)$ & $36(29)$ & $36(28)$ \\
\hline Serum creatinine, $\mu \mathrm{mol} / \mathrm{l}$ & $83(26)$ & $85(27)$ & $85(26)$ \\
\hline Serum sodium, mmol/l & $136(4.5)$ & $136(4.4)$ & $136(4.4)$ \\
\hline Refractory ascites, n & $100(59.5 \%)$ & $206(62.8 \%)$ & $306(61.7 \%)$ \\
\hline Number of paracenteses in last year & $7.6(7.8)$ & $7.5(8.8)$ & $7.5(8.5)$ \\
\hline Time since last paracentesis, days & $24.4(19.1)$ & $25.2(21.6)$ & $24.9(20.8)$ \\
\hline Volume of ascites removed at baseline, I & $6.3(2.4)$ & $6.3(2.3)$ & $6.3(2.3)$ \\
\hline History of hepatic encephalopathy, n & $47(28.0 \%)$ & $82(25.1 \%)$ & $129(26.1 \%)$ \\
\hline
\end{tabular}

Values are mean (SD) or $\mathrm{n}(\%)$.

*Some patients may have more than one aetiology of cirrhosis.

MELD, model for end-stage liver disease. ment-related events leading to permanent discontinuation of treatment $(33.6 \%$ vs $28.3 \%$ ) did not differ significantly between the two treatment groups. Among the various types of adverse events reported, the incidence of gastrointestinal (GI) bleeding events showed the most marked difference between the treatment groups (upper GI bleeding $10.9 \%$ vs $6.0 \%$; lower GI bleeding $3.3 \%$ vs $1.8 \%$ ). Renal events overall were also more frequent in the satavaptan group (30.9\% vs $24.7 \%$ ) but, within that category, major events such as renal failure $(7.0 \%$ vs $9.0 \%)$ and hepatorenal syndrome $(7.0 \%$ vs $7.8 \%)$ were reported less frequently compared with placebo. The frequency of hyperkalaemia was similar in the two groups (satavaptan $27.4 \%$ vs placebo $30.1 \%$ ).

During the 52 weeks of follow-up $29.4 \%$ of patients in the satavaptan group and $21.7 \%$ in the placebo group died (RR for all-cause mortality during or after treatment $1.47,95 \%$ CI 1.01 to $2.15, p=0.049$; figure 3 ). The incidence of treatment-related events with a fatal outcome was also higher in the satavaptan group than in the placebo group (14.8\% vs $8.4 \%$; RR $1.82,95 \%$ CI 1.00 to 3.29 ). Most deaths were associated with known complications of liver cirrhosis (table 2).

\section{Study 3: Satavaptan versus placebo as single therapy in the prevention of recurrent ascites after LVP}

The disposition of all the patients is shown in figure 6 in the online supplement. After completion of enrollment but before the treatment of all patients had been completed, the Drug Safety Monitoring Board recommended the early termination of this study due to poor risk-benefit. At that time, 21 patients $(13.0 \%)$ in the satavaptan group and 10 patients $(12.5 \%)$ in the placebo group were still receiving treatment.

The average duration of exposure to study treatment was longer in the satavaptan group than in the placebo group (median duration 152 days vs 76 days), mainly due to a higher drop-out rate for lack of efficacy and patients leaving the study for unspecified reasons in the placebo group.

Compared with patients in studies 1 and 2 , patients in study 3 had more advanced liver disease and almost all had refractory ascites (table 4).

There was no statistically significant effect in the first 12 weeks on the cumulative number of LVPs in the satavaptan group compared with the placebo group (RR 0.90, 95\% CI 0.74 to 1.09; figure 4), although there was a trend for better efficacy in the satavaptan group. There was also no statistical significance between the two groups over 52 weeks of treatment.

The time to first LVP (RR $0.72,95 \%$ CI 0.53 to 0.98 , $\mathrm{p}=0.0354$ ) and time to first recurrence of ascites ( $R R \quad 0.67,95 \%$ CI 0.50 to $0.89, p=0.0063$; figure 7 in online supplement) were both increased by satavaptan compared with placebo. The mean cumulative increase in ascites was estimated to be $3.5 \mathrm{l} /$ week for satavaptan and $3.61 /$ week for placebo, a ratio of $0.97,95 \% \mathrm{CI}$ 0.78 to $1.15(\mathrm{p}=0.7334)$.

In patients with significant hyponatraemia at study entry, the median time to correction of hyponatraemia was 7 days in the satavaptan group and 30 days in the placebo group (RR 2.26, $95 \%$ CI 1.22 to 4.17 ). The percentage of patients in the study with a serum sodium level $>145 \mathrm{mmol} / \mathrm{l}$ was higher in the satavaptan group than in the placebo group (13.0\% vs $5.1 \%$ ). Three patients in the satavaptan group compared with one patient in the placebo group had an initial increase in serum sodium of $\geq 8 \mathrm{mmol} / \mathrm{l}$ in the $24 \mathrm{~h}$ following the first dose of the study treatment. The maximum increase was $12 \mathrm{mmol} / \mathrm{l}$ and these changes were not associated with any adverse clinical events. The incidence of other major complications of cirrhosis 
Figure 2 Cumulative number of largevolume paracenteses in study 2 : satavaptan versus placebo in combination with diuretics in the prevention of recurrent ascites after large-volume paracentesis (RR 0.89, $95 \%$ Cl 0.76 to 1.05$)$.

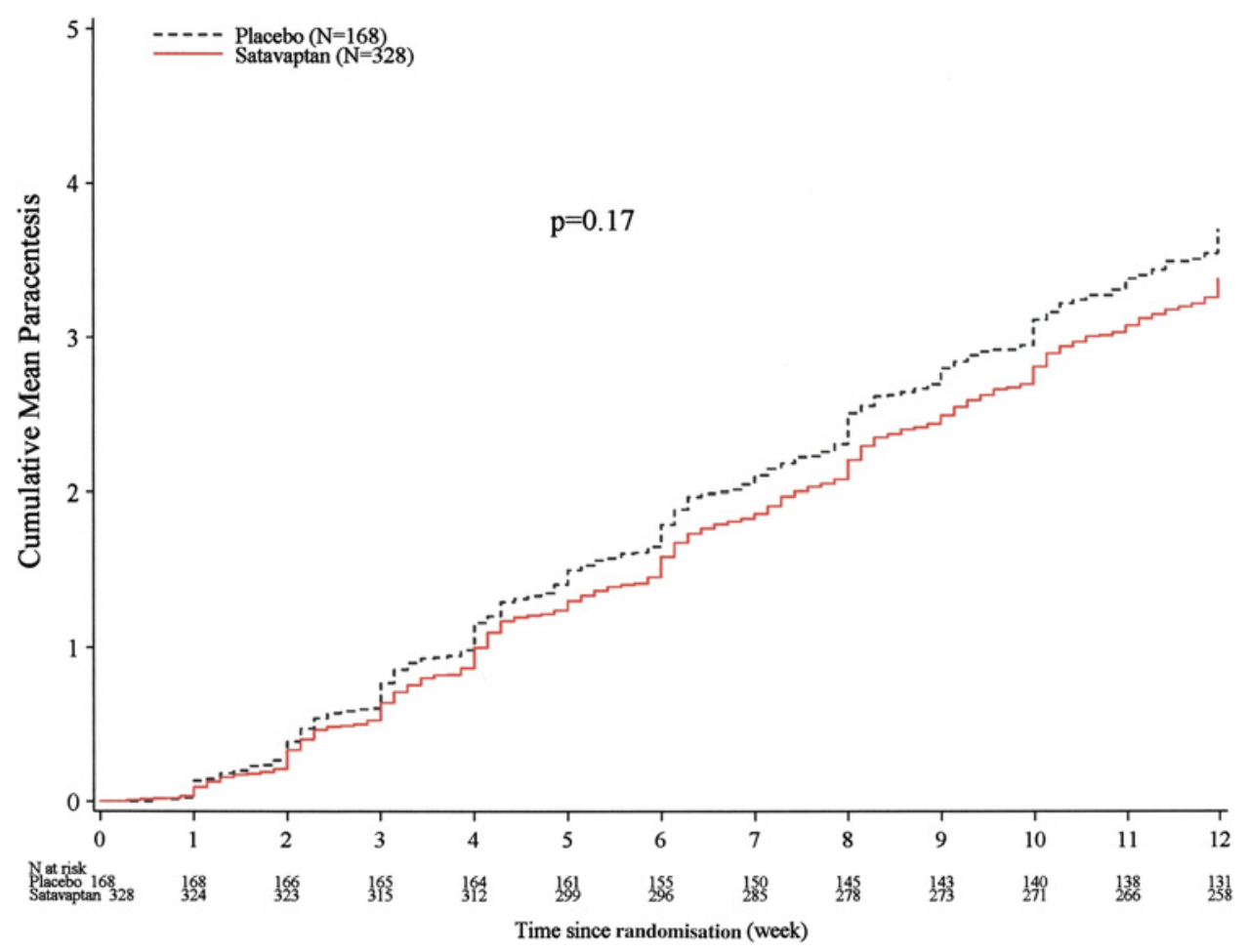

did not differ significantly between the two treatment arms (see table 6 in online supplement).

During follow-up, significant increases in serum bilirubin (threefold) were more frequent in the satavaptan group than in the placebo group (Kaplan-Meier 52-week estimates $17.6 \%$ vs $1.7 \%)$. However, the frequency of elevations of liver transaminases did not differ. There was also a higher frequency of modest increases $(>30 \%)$ in serum creatinine with satavaptan (Kaplan-Meier 52-week estimates $69.1 \%$ vs $45.5 \%$ ) but no difference in the frequency of more marked increases.
Comparison of renal function tests (serum creatinine and MDRD), other serum chemistries, haematological parameters and arterial pressure and heart rate (see table 4 in the online supplement) did not show any substantial differences between the treatment groups, but ECG analysis showed that 10 patients $(6.3 \%)$ in the satavaptan group had a OTcF interval $\geq 500 \mathrm{~ms}$ compared with no patients in the placebo group.

Overall, the percentage of patients with any treatment-related adverse events (87.0\% for satavaptan vs $87.3 \%$ for placebo), serious treatment-related events $(60.9 \%$ vs $58.2 \%)$ and
Figure 3 Kaplan-Meier analysis of all-cause mortality up to 52 weeks in study 2: satavaptan versus placebo in combination with diuretics in the prevention of recurrent ascites after large-volume paracentesis (RR 1.47, $95 \% \mathrm{Cl} 1.01$ to $2.15, \mathrm{p}=0.049$ ).

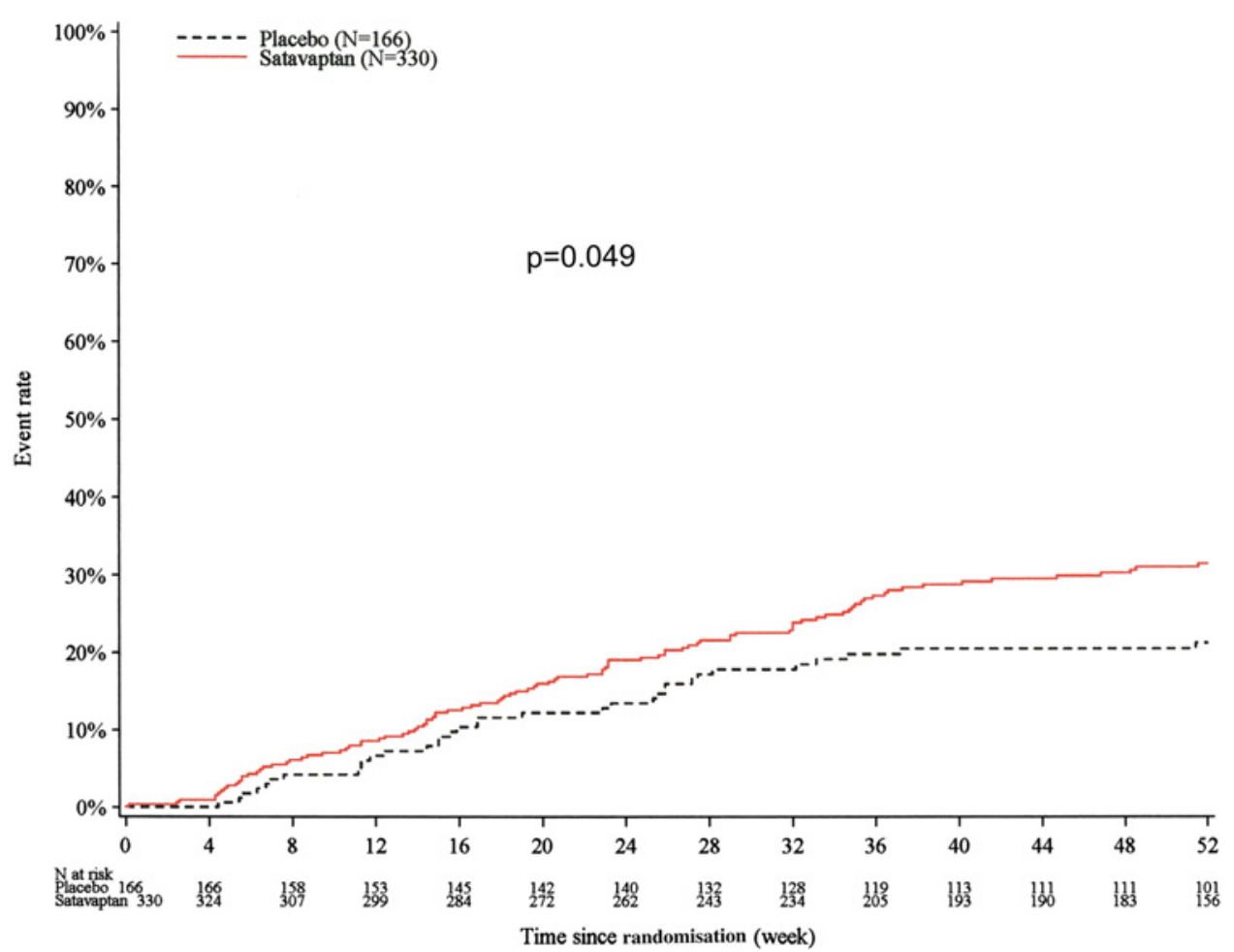


Table 4 Baseline characteristics of patients included in study 3: satavaptan versus placebo as single therapy in the prevention of recurrent ascites after large-volume paracentesis

\begin{tabular}{lccc}
\hline & $\begin{array}{c}\text { Placebo } \\
\text { (N=80) }\end{array}$ & $\begin{array}{c}\text { Satavaptan } \\
(\mathbf{N}=160)\end{array}$ & $\begin{array}{l}\text { All } \\
\text { (N=240) }\end{array}$ \\
\hline Age, years & $56.2(9.9)$ & $56.4(9.6)$ & $56.3(9.7)$ \\
Sex & & & \\
$\quad$ Men & $50(62.5 \%)$ & $108(67.5 \%)$ & $158(65.8 \%)$ \\
$\quad$ Women & $30(37.5 \%)$ & $52(32.5 \%)$ & $82(34.2 \%)$ \\
Aetiology of cirrhosis, $\mathrm{n}^{*}$ & & & \\
$\quad$ Alcoholism & $45(56.3 \%)$ & $102(64.2 \%)$ & $147(61.5 \%)$ \\
$\quad$ Hepatitis B & $5(6.3 \%)$ & $13(8.2 \%)$ & $18(7.5 \%)$ \\
$\quad$ Hepatitis C & $24(30.0 \%)$ & $32(20.1 \%)$ & $56(23.4 \%)$ \\
$\quad$ Others & $13(16.2 \%)$ & $29(18.1 \%)$ & $42(17.5 \%)$ \\
Child-Pugh score & $9.3(1.7)$ & $8.9(1.6)$ & $9.0(1.6)$ \\
Child-Pugh class C, $\mathrm{n}$ & $37(46.3 \%)$ & $50(31.3 \%)$ & $87(36.3 \%)$ \\
MELD score & $14.4(4.6)$ & $13.7(4.3)$ & $13.9(4.4)$ \\
MELD-Na score & $19.1(9.4)$ & $16.8(7.4)$ & $17.6(8.2)$ \\
Serum bilirubin, $\mu$ mol/l & $43(34)$ & $35(26)$ & $38(29)$ \\
Serum creatinine, $\mu$ mol/l & $84(28)$ & $84(26)$ & $84(27)$ \\
Serum sodium, mmol/I & $134(6)$ & $135(5)$ & $135(6)$ \\
Refractory ascites, $\mathrm{n}$ & $72(90.0 \%)$ & $149(93.1 \%)$ & $221(92.1 \%)$ \\
Number of paracenteses in last year & $7.9(9.0)$ & $8.2(10.1)$ & $8.1(9.7)$ \\
Time since last paracentesis, days & $27.1(27.0)$ & $26.5(26.3)$ & $26.7(26.5)$ \\
Volume of ascites removed at baseline, I & $6.0(2.1)$ & $6.1(2.7)$ & $6.1(2.5)$ \\
History of hepatic encephalopathy, $\mathrm{n}$ & $26(32.5 \%)$ & $52(32.5 \%)$ & $78(32.5 \%)$ \\
\hline
\end{tabular}

Values are mean (SD) or $\mathrm{n}(\%)$.

*Some patients may have more than one aetiology of cirrhosis.

MELD, model for end-stage liver disease.

treatment-related events leading to permanent discontinuation of treatment (40.4\% vs $35.4 \%$ ) did not differ significantly between the two treatment groups. Among the various types of adverse events reported, there was no single type of event for which the risk of occurrence was increased in the satavaptan group when taking into account the difference in duration of treatment and observation between the two groups.
During the 52 weeks of follow-up $34.2 \%$ of patients in the satavaptan group and $34.2 \%$ in the placebo group died (RR for all-cause mortality during or after treatment 0.95 , 95\% CI 0.60 to 1.51; figure 5). The risk of a treatment-related event with a fatal outcome on satavaptan was 1.68 (95\% CI 0.74 to 3.83). Most deaths were associated with known complications of cirrhosis (table 2).

\section{DISCUSSION}

Clinical research in patients with cirrhosis has focused recently on the potential beneficial effects of vaptans in the management of renal sodium and water retention. ${ }^{8-10} 12-14$ The rationale is that plasma vasopressin levels are increased in advanced cirrhosis and contribute to hypervolaemic hyponatraemia. ${ }^{1}{ }^{15} 16 \mathrm{~A}$ number of studies have shown that vaptans improve serum sodium in patients with hyponatraemia without significant side effects except for thirst. ${ }^{5-10} 12$ However, the efficacy of vaptans in the management of ascites has not been evaluated thoroughly. The results of the three studies reported here indicate that satavaptan is of limited efficacy in the control of ascites across the different groups of patients with ascites. This was the reason for reporting the three studies together. The results of the current study are in contrast with results of phase II studies showing that satavaptan reduced ascites volume and the need for paracentesis. ${ }^{8-10}$ None of the primary efficacy endpoints showed significant differences compared with placebo, which clearly indicates that satavaptan is not effective in the management of ascites either alone or in combination with diuretics. On the basis of these results, more research on the potential use of vaptans in the management of ascites does not seem to be justified. There were, however, statistically significant differences in some secondary endpoints, suggesting a slight advantage of satavaptan over placebo in delaying the accumulation of ascites. For example, in patients with ascites not requiring LVP (study 1), satavaptan was more effective than placebo in the reduction of ascites volume but was not effective
Figure 4 Cumulative number of largevolume paracenteses in study 3 : satavaptan versus placebo as single therapy in the prevention of recurrent ascites after large-volume paracentesis (RR $0.90,95 \% \mathrm{Cl} 0.74$ to 1.09 ).

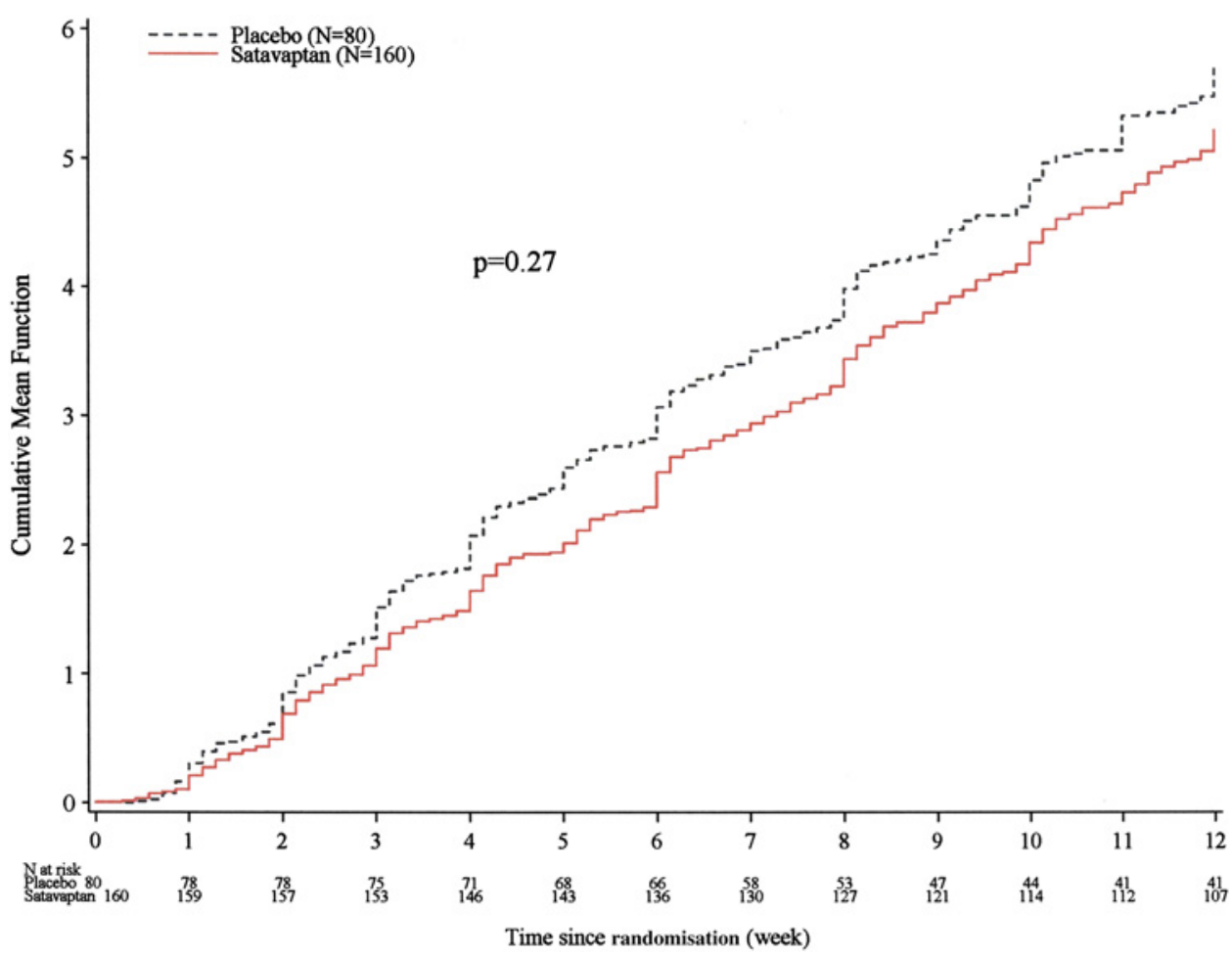


Figure 5 Kaplan-Meier analysis of all-cause mortality in study 3 : satavaptan versus placebo as single therapy in the prevention of recurrent ascites after large-volume paracentesis (RR $0.95,95 \% \mathrm{Cl} 0.60$ to $1.51, \mathrm{p}=\mathrm{NS}$ ).

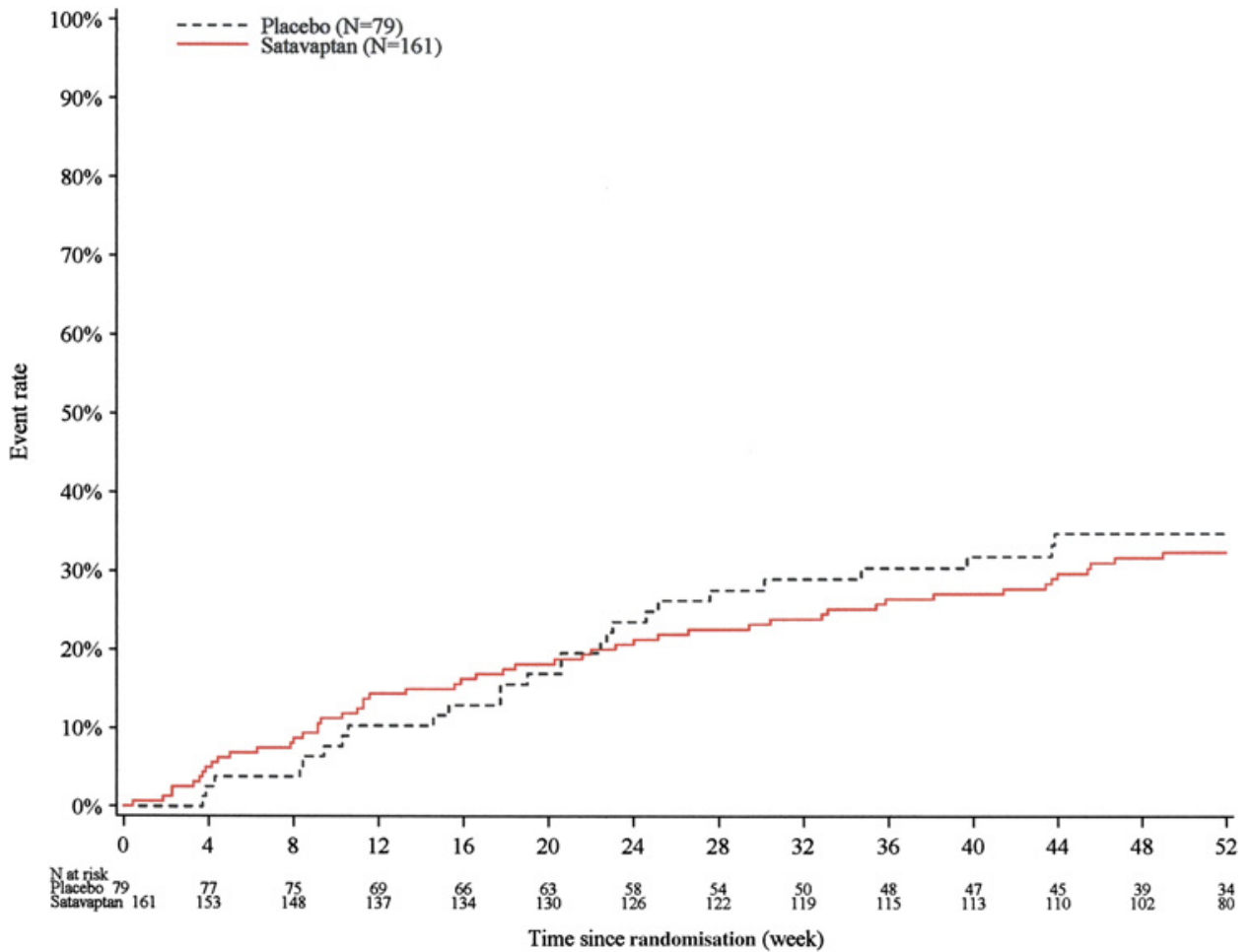

overall in the prevention of ascites worsening, which was the primary endpoint. Similarly, in patients with difficult-to-treat ascites requiring frequent LVP (studies 2 and 3) there was a slight but significant reduction in the reaccumulation of ascites and time to first recurrence of ascites, but treatment with satavaptan did not reduce the number of LVPs over a 12-week period compared with placebo. The dose of satavaptan used in the current studies was not fixed and was in the low range of the doses used in phase II studies $(5-10 \mathrm{mg} /$ day vs $5-25 \mathrm{mg} /$ day, respectively). However, it seems unlikely that this could have contributed to the lack of efficacy of the drug because, in the only phase II study in which patients received satavaptan for a period of time similar to that used in the current studies to assess the primary endpoints (12 weeks), the $5 \mathrm{mg}$ /day dose was similarly effective to the 12.5 and $25 \mathrm{mg}$ /day doses in the prevention of ascites recurrence. ${ }^{10}$ In contrast to the lack of efficacy in the management of ascites, satavaptan was more effective than placebo in improving the serum sodium concentration in patients with hyponatraemia in the three populations studied.

Besides the lack of clinically significant benefit of the use of satavaptan in the management of ascites, the results of one of the studies (study 2) show an increased risk of death in patients treated with satavaptan compared with placebo. Surprisingly, this effect was not observed in the other two studies. The cause of this increased risk of death is both uncertain and intriguing and was not related to geographical variations in the risk of dying. There are a number of possible explanations. First, the increased mortality could be related to the intrinsic effect of the drug in increasing solute-free water excretion with potentially subsequent dehydration and/or hypernatraemia. ${ }^{5}$ However, although the frequency of hypernatraemia during follow-up was slightly higher with satavaptan that with placebo, this was not associated with clinically relevant side effects and in all cases the serum sodium concentration recovered after treatment was temporarily stopped. Moreover, the number of patients treated with satavaptan who had sharp increases in the serum sodium concentration ( $\geq 8 \mathrm{mmol} / \mathrm{l}$ ) was very low and none of them developed neurological complications. Second, it is possible that satavaptan, in association with diuretics, by increasing urine losses could result in hypovolaemia and subsequent renal failure. Nonetheless, the frequency of renal failure, which is a fairly common complication in patients with ascites, was similar in the satavaptan and placebo groups across the three different patient populations. Moreover, the results of these phase III studies as well as those of phase II studies indicate that treatment with satavaptan in association with diuretics does not result in an impairment of circulatory function. ${ }^{6-8}$ A third possible explanation is that satavaptan could, for some unknown reason, increase the risk of complications of cirrhosis leading to a higher mortality. Nevertheless, the frequency of complications of cirrhosis was similar in the satavaptan and placebo groups in study 2 and also in studies 1 and 3. In two of the three studies there was a higher frequency of increased serum transaminasses (study 2) and bilirubin (studies 2 and 3 ) in patients in the satavaptan group compared with those in the placebo group. Although there is no evidence for satavaptaninduced liver injury in phase II studies or in long-term animal toxicology studies, this possibility cannot be completely excluded. Finally, we cannot rule out that the increased risk of death observed in study 2 was due to a type 1 error. In fact, differences in the risk of death between satavaptan and placebo groups were only significant at 52 weeks and not in early periods of follow-up ( 3 and 6 months), and the difference was only just at the level of significance $(p=0.049)$. In this regard, it is also important to note that 97 patients (64 in the satavaptan group and 33 in the placebo group) had not finished the follow-up at the time of study discontinuation. Moreover, the observation that mortality in the satavaptan and placebo groups in the other two populations of patients (studies 1 and 3) was almost identical casts doubt on the possibility that satavaptan has a direct negative effect on the natural history of cirrhosis with ascites. 
The purpose of these three studies was not to assess the effects of satavaptan on the management of hyponatraemia but on the management of ascites. Therefore, the lack of efficacy of satavaptan on the management of ascites does not negate the results of numerous previous studies showing that vaptans are efficacious in improving the serum sodium concentration in patients with cirrhosis and dilutional (hypervolaemic) hyponatraemia. ${ }^{7}$ 11-13 $^{15}$ Nevertheless, these results call for appropriately designed studies to investigate the safety and efficacy of vaptans in the long-term management of hyponatraemia in cirrhosis.

Funding Supported by Sanofi Aventis.

Competing interests This study was funded in part by Sanofi Aventis. FW and PG have acted on a consultancy basis for Sanofi Aventis. HW and SB are employees of Sanofi Aventis.

Ethics approval Ethics approval was provided by the ethics committees of the various hospitals involved.

Contributors PG and HW were directly involved in the design and writing of the paper. All authors reviewed and commented on the paper and have given their final approval for the paper and its content.

Provenance and peer review Not commissioned; externally peer reviewed.

\section{REFERENCES}

1. Moore K, Wong F, Ginès $P$, et al. The management of ascites in cirrhosis: report of a consensus conference of the International Ascites Club. Hepatology 2003:38:258-66.

2. European Association for the Study of the Liver. EASL clinical practice guidelines on the management of ascites, spontaneous bacterial peritonitis and hepatorenal syndrome in cirrosis. J Hepatol 2010;53:397-417.

3. Gerbes $\mathbf{A L}$, ed. Ascites, hyponatremia and hepatorenal syndrome: progress in treatment. Frontiers of Gastrointestinal Research. Volume 28. Basel: Karger, 2011.
4. Runyon BA; AASLD Practice Guidelines Committee. Management of adult patients with ascites due to cirrhosis: an update. Hepatology 2009;49:2087-107.

5. Decaux G, Soupart A, Vassart G. Non-peptide arginine-vasopressin antagonists: the vaptans. Lancet 2008;371:1624-32.

6. Ghali JK, Koren MJ, Tayolor JR, et al. Efficacy and safety of oral conivaptan: a V1/ V2 vasopressin receptor antagonist, assessed in a randomized placebo-controlled trial in patients with euvolemic or hypervolemic hyponatremia. J Clin Endocrinol Metab 2006;91:2145-52.

7. Schrier RW, Gross P, Gheorghiade M, et al; SALT Investigators. Tolvaptan, a selective oral vasopressin V2-receptor antagonist, for hyponatremia. N Engl J Med 2006;355:2099-112.

8. Ginès $\mathbf{P}$, Wong $\mathrm{F}$, Watson $\mathrm{H}$, et al; HypoCAT Study Investigators. Effects of satavaptan, a selective vasopressin V(2) receptor antagonist, on ascites and serum sodium in cirrhosis with hyponatremia: a randomized trial. Hepatology 2008:48:204-13

9. Ginès $\mathbf{P}$, Wong $\mathrm{F}$, Watson $\mathrm{H}$, et al; for the Normocat Study Investigators. Clinical trial: short-term effects of combination of satavaptan, a selective vasopressin V2 receptor antagonist, and diuretics on ascites in patients with cirrhosis without hyponatremia-a randomized, double-blind, placebo-controlled study. Aliment Pharmacol Ther 2010;31:834-45.

10. Wong $\mathbf{F}$, Ginès $P$, Watson $H$, et al. Effects of a selective vasopressin $V 2$ receptor antagonist, satavaptan, on ascites recurrence after paracentesis in patients with cirrhosis. J Hepatol 2010;53:283-90.

11. Levey AS, Bosch JP, Lewis JB, et al. A more accurate method to estimate glomerular filtration rate from serum creatinine: a new prediction equation. Modification of Diet in Renal Disease Study Group. Ann Intern Med 1999;130:461.

12. Gerbes AL, Gülberg VA, Ginès P, et al; VPA Study Group. Therapy of hyponatremia in cirrhosis with a vasopressin receptor antagonist: a randomized, double-blind multicenter trial. Gastroenterology 2003;124:933-9.

13. Wong F, Blei AT, Blendis LM, et al. A vasopressin receptor antagonist (VPA-985) improves serum sodium concentration in patients with hyponatremia: a multicenter, randomized, placebo-controlled trial. Hepatology 2003;37:182-91.

14. Guyader D, Patat A, Ellis-Grosse J, et al. Pharmacodynamic effects of a nonpeptide antidiuretic hormone V2 antagonist in cirrhotic patients with ascites. Hepatology 2002;36:1197-205.

15. Ginès $\mathbf{P}$, Berl $T$, Bernardi $M$, et al. Hyponatremia in cirrhosis: from pathogenesis to treatment. Hepatology 1998;28:851-64.

16. Ginès $\mathbf{P}$, Guevara $\mathrm{M}$. Hyponatremia in cirrhosis: pathogenesis, clinical significance, and management. Hepatology 2008;48:1002-10.

Gut online

Visit Gut online and listen to the latest podcast, post comments and download any you might have missed. Keep informed and up to date by visiting gut.bmj.com. 


\section{GUT Satavaptan for the management of ascites in cirrhosis: efficacy and safety across the spectrum of ascites severity}

Florence Wong, Hugh Watson, Alexander Gerbes, Hendrik Vilstrup, Salvatore Badalamenti, Mauro Bernardi, Pere Ginès and for the Satavaptan Investigators Group

Gut 2012 61: 108-116 originally published online August 11, 2011 doi: 10.1136/gutjnl-2011-300157

Updated information and services can be found at:

http://gut.bmj.com/content/61/1/108

Supplementary
Material

References

Email alerting service
Supplementary material can be found at: http://gut.bmj.com/content/suppl/2011/09/14/gutjnl-2011-300157.DC2. html

http://gut.bmj.com/content/suppl/2011/08/25/gutjnl-2011-300157.DC1. html

These include:

This article cites 15 articles, 0 of which you can access for free at: http://gut.bmj.com/content/61/1/108\#BIBL

Receive free email alerts when new articles cite this article. Sign up in the box at the top right corner of the online article.

Topic Articles on similar topics can be found in the following collections Collections

\section{Notes}

To request permissions go to:

http://group.bmj.com/group/rights-licensing/permissions

To order reprints go to:

http://journals.bmj.com/cgi/reprintform

To subscribe to BMJ go to:

http://group.bmj.com/subscribe/ 